\title{
CARDINAL, Claudette, The History of Quebec: A Bibliography of Works in English. Sous la direction de Graeme Decaire et Ronald Rudin, Centre for the Study of Anglophone Quebec, Université Concordia, 1981. 202 p.
}

\section{Robin B. Burns}

Volume 37, numéro 3, décembre 1983

URI : https://id.erudit.org/iderudit/304184ar

DOI : https://doi.org/10.7202/304184ar

Aller au sommaire du numéro

Éditeur(s)

Institut d'histoire de l'Amérique française

ISSN

0035-2357 (imprimé)

1492-1383 (numérique)

Découvrir la revue

Citer ce compte rendu

Burns, R. B. (1983). Compte rendu de [CARDINAL, Claudette, The History of Quebec: A Bibliography of Works in English. Sous la direction de Graeme Decaire et Ronald Rudin, Centre for the Study of Anglophone Quebec, Université Concordia, 1981. 202 p.] Revue d'histoire de l'Amérique française, 37(3), 455-456. https://doi.org/10.7202/304184ar d'utilisation que vous pouvez consulter en ligne. 
CARDINAL, Claudette, The History of Quebec: A Bibliography of Works in English. Sous la direction de Graeme Decaire et Ronald Rudin, Centre for the Study of Anglophone Quebec, Université Concordia, 1981. 202 p.

Cette bibliographie est la première publication du «Centre for the Study of Anglophone Quebec» de l'Université Concordia. Il aurait fallu nommer le centre «Centre for the Study of English-Speaking Quebec» puisque le mot «anglophone» n'est pas un mot anglais, du moins pas encore. Le codirecteur, le professeur Ronald Rudin, explique en introduction que la bibliographie s'adresse aux anglophones québécois qui désirent étudier l'histoire de leur province et de leur milieu. Ce motif, de même que la floraison de travaux en anglais, sont les raisons données pour justifier la décision de limiter la collection aux seuls titres anglais.

Était-ce une décision souhaitable? Les anglophones québécois sont-ils si unilingues? Certainement pas pour la nouvelle génération d'étudiants anglophones. Beaucoup ont gradué de programmes d'immersion en français, certains ayant même poursuivi des études dans des écoles élémentaires, secondaires et des collèges français. Il leur est donc facile de lire en français. N'est- 
ce pas un danger que le Centre donne l'impression fausse que les nouveaux anglophones québécois sont encore des unilingues entêtés.

Il va sans dire que la bibliographie n'est pas uniquement rédigée pour les universitaires. Une des meilleures réussites du Centre a été son effort pour susciter l'intérêt de la communauté anglophone en général. Mais l'ouvrage peut laisser l'impression au lecteur non averti qui consulte la bibliographie que les recherches en histoire au Québec sont terminées. Il y a danger aussi que l'approche choisie contribue à renforcer les murs du ghetto linguistique plutôt que de les abattre. Une étude sur l'historiographie canadienne-française aurait contribué à éviter ce danger. Le professeur Rudin étant lui-même un excellent historien avec une connaissance étendue de l'historiographie du Québec, le lecteur aurait grandement bénéficié qu'il ajoute une étude sur les tendances de l'histoire et des historiens canadiens-français.

La bibliographie est divisée en six parties. La première, "Tools", comprend des travaux de référence, une liste de revues, des travaux généraux divisés en six périodes, des biographies et des mémoires. La liste des revues n'inclut pas les années de publication ni une brève description qui aideraient le lecteur à identifier le sujet de la revue. Les quatres parties suivantes sont subdivisées selon les catégories traditionnelles d'histoire économique, sociale, politique et culturelle. La dernière partie, "Special Areas" est consacrée à l'histoire des régions, des villes, des femmes et des Amérindiens. Il y a un index par auteur mais pas par sujet. Ce n'est pas une omission sérieuse parce que la table des matières est très détaillée.

Si cette bibliographie stimule l'étude de l'histoire du Québec et amène le lecteur à réaliser que l'on doit pouvoir lire en français pour étudier convenablement le sujet, alors la première publication du Centre s'avérera utile. Nous espérons que ce sera le cas.

Département d'histoire

Bishop's University

ROBIN B. BURNS 